\title{
La restauración de la Iglesia católica en la transición mexicana
}

doi: http://dx.doi.org/10.32870/espiral.v22i64.2925.g2653 Germán Petersen Cortés•

Las funciones de la Iglesia en el sistema político mexicano, y la interacción de esta con el Estado mexicano, han sido temas ampliamente investigados por antropólogos, sociólogos e historiadores. La amplia literatura al respecto proveniente de estas disciplinas contrasta con la escasez de trabajos al respecto provenientes de la ciencia política. La ciencia política mexicana ha tratado más bien marginalmente las cuestiones religiosas, aunque -paradójicamente-quizá sean más políticas que muchas otras cosas.

El más reciente libro de Soledad Loaeza utiliza el instrumental de la ciencia política para analizar los papeles que fue adoptando la Iglesia a lo largo de la democratización del régimen mexicano, con especial atención a su relación con el Estado. El argumento central del libro es que, a lo largo de los últimos 30 años, en el periodo denominado "transición mexicana a la democracia”, la Iglesia logró una restauración política, trascendiendo el bajo perfil al que fue conducida por el Estado posrevolucionario. Para la autora, si bien es cierto que la Iglesia católica mantuvo privilegios durante el régimen autoritario que dominó al país la mayor parte del siglo XX, no gozó de la autonomía que le permitió la democratización

Soledad Loaeza (2013). La restauración de la Iglesia católica en la transición mexicana. México: El Colegio de México. 
ni mucho menos tuvo las posibilidades de restauración que se abrieron con esta.

El libro es una recopilación de artículos académicos -los más-y de divulgación-los menos- publicados por Loaeza en libros y revistas de México, Estados Unidos y Francia entre 1984 y 2010 . Dado que la mayor parte de estos análisis se escribieron mientras se desenvolvía el proceso bajo estudio, no retrospectivamente, se acota el paso al error común de interpretar lo sucedido en el pasado a la luz de su desenlace. Aun cuando se trata de artículos pensados como unidades en sí mismas o como capítulos de otros libros, no como componentes de esta obra, se advierte un hilo conductor, que es justamente el creciente protagonismo de la Iglesia católica en la política mexicana desde el arranque de la transición hasta la fecha. Este protagonismo de la Iglesia se expresó de diversas maneras: acercamiento de las relaciones diplomáticas entre México y el Vaticano, aprobación de reformas constitucionales favorables a la Iglesia, e intentos de la Iglesia por incidir en los valores de los mexicanos mediante la educación, por citar algunos ejemplos.

Todos los capítulos se refieren a México, salvo el primero, que se refiere a América Latina. En este capítulo inicial se ofrece un panorama de la Iglesia en la región, analizando sus cambios y continuidades durante la segunda mitad del siglo XX, con especial atención a cuatro asambleas generales de la Conferencia del Episcopado Latinoamericano: Río de Janeiro (1955), Medellín (1968), Puebla (1979) y Santo Domingo (1992). Así como el capítulo primero expone el contexto regional, el segundo plantea el contexto histórico para el caso de México, sintetizando el papel político de la Iglesia y su relación con el Estado de 1940 a los sesenta, es decir, las décadas previas al comienzo de la democratización $y$, por ende, del proceso que la autora interpreta como una restauración política de la Iglesia. Fue de los cuarenta a los sesenta que la relación entre Iglesia y Estado transitó de las 
tensiones producto de los múltiples choques entre ambas instituciones en los años posteriores a la Revolución, a la colaboración de mutuo beneficio, en el arreglo denominado "modus vivendi".

Los capítulos cuarto, quinto y noveno analizan sistemáticamente la restauración política de la Iglesia entre 1970 y 1994, así como el rol del Estado en este proceso. Se trata, por tanto, de los capítulos que aportan la evidencia que sostiene el argumento central del libro. Los capítulos sexto al décimo y décimo segundo se enfocan en periodos o aspectos específicos de este periodo. Ahí se abordan asuntos como la relación entre la Iglesia y la democratización, la memoria y el olvido de los múltiples conflictos entre Iglesia y Estado en México, y el papel de la Iglesia en Chiapas en el levantamiento zapatista de 1994.

Los capítulos tercero y décimo cuarto versan sobre las estrategias de la Iglesia para aprovechar el contexto de la Guerra Fría y, específicamente, el anticomunismo de la época, para hacer prevalecer sus valores en la construcción de la femineidad. En los capítulos décimo tercero y décimo quinto, la autora también aborda las estrategias de la Iglesia para que sus valores prevalezcan, respectivamente, en la educación de niños y jóvenes y en asuntos ampliamente discutidos en el México de hoy, como la interrupción legal del embarazo y los derechos de las parejas del mismo sexo. Loaeza apunta las múltiples contradicciones entre estas posturas de la Iglesia y las de aquellos segmentos secularizados de la sociedad mexicana. Estos cuatro capítulos constituyen un mirador para observar la articulación entre religión, política, cultura, derecho y moral.

El enfoque de Loaeza es institucionalista, por lo que la investigación subraya la dimensión organizativa de la política, la centralidad de las reglas en las interacciones de poder y las contradicciones tanto entre instituciones como dentro de cada institución. Si bien el acento de la obra está 
colocado en lo político, no se pierde de vista la relación de esto con las demás esferas de la sociedad, sobre todo analizando la interacción entre la participación política de la Iglesia y las tendencias ideológicas de la época. Los alcances y límites del protagonismo político de la Iglesia están en buena medida condicionados por las visiones del mundo dominantes y las afrentas que estas reciben de visiones que les son contrarias.

El grado de abstracción que mantiene la autora a lo largo de la obra le permite distinguir la trayectoria política de la Iglesia en el siglo XX mexicano, sin perder fundamento empírico en sus explicaciones. Dicho en otros términos, la argumentación se centra en macroinstituciones, como la Iglesia, el Estado y el sistema político, y se enfoca en la escala nacional, lo que prácticamente obliga a un alto grado de abstracción; sin embargo, esto no obsta para que las explicaciones estén cimentadas sobre evidencia.

El trabajo de Loaeza revela que la Iglesia está en un cambio continuo, aun cuando frecuentemente se jacte de lo contrario. Al estudiar a la Iglesia desde una perspectiva histórica, la autora pone en relieve el carácter cambiante de su participación política, en oposición a visiones que, consciente o inconscientemente, hacen énfasis en la continuidad. Otra de las fortalezas metodológicas del trabajo es que no aísla la política nacional de la internacional ni de las grandes tendencias globales. De hecho, Loaeza no sólo toma en cuenta factores internacionales de evidente impacto sobre la Iglesia mexicana, como la relación diplomática entre México y El Vaticano, sino también otros acontecimientos importantes para el catolicismo a nivel mundial y, por ende, para el mexicano, como el Concilio Vaticano II, el papel de la Iglesia en la caída de los regímenes socialistas de Europa del Este y la tensión bipolar de la Guerra Fría. 
El trabajo profundiza en las élites religiosas y políticas, en una lectura arriba-abajo de lo que la autora sostiene es la restauración política de la Iglesia. Un buen complemento de esta perspectiva sería centrarse en el papel de los católicos "de a pie" en esta restauración, en una lectura abajoarriba. Sería especialmente interesante conocer el papel que desempeñaron en este proceso aquellos católicos que se organizaron políticamente de manera autónoma a las directrices del magisterio y hasta en franca contraposición con algunos sectores de este.

En la "Introducción", Loaeza condensa una de las múltiples provocaciones intelectuales a las que invita al lector. "La Iglesia recuperó la plena autonomía en México gracias a la democracia, al pluralismo político y a la diversidad social; es de esperar que ella misma se haya comprometido con estos tres procesos en los que siempre vio un adversario" (p. 12). Queda la duda de si la Iglesia se comprometerá con el pluralismo mexicano en el futuro, pero es un hecho que hasta ahora ha mostrado, cuando menos, ambivalencia.

El trabajo de Loaeza, por la originalidad de su argumento central y la consistencia de los argumentos secundarios respecto al central, seguramente se convertirá en un referente para entender el papel político de la Iglesia en el México contemporáneo. El libro es lectura obligada no sólo para los especialistas en cuestiones religiosas, sino para todos los interesados en el sistema político mexicano, y más particularmente para quienes pretenden lograr una comprensión amplia de este, que no se limite a las instituciones tradicionalmente consideradas como políticas. Para los politólogos el libro es aun de mayor importancia, pues además de que invita al estudio de una institución más bien marginal en la ciencia política mexicana, aporta claves metodológicas para investigarla con las herramientas propias de la disciplina. 